\title{
Adaptive control of public lighting
}

\begin{abstract}
Public lighting is a specific type of lighting system, which various requirements. It is a lighting system which is subject to many influences. Some impacts are changing very rapidly but a lighting system is designed for a specific case. These effects are for example traffic density, conflict situations and the impact of weather. Comprehensive regulation taking into account all the effects not currently exist but particular systems taking into account the subtasks are occuring.

Paper describes possible ways to control lighting systems based on current conditions. The aim is to show the possibilities and also the technical prerequisites for the realization of such systems. Described technology is currently in its early stages and pilots projects are preparing. Aim of this paper is give information about technology and open discuss about adaptive public lighting.
\end{abstract}

Keywords: public lighting, smart grid, adaptive control

\section{Introduction}

Public lighting is now in all larger towns and in al municipalities in Slovakia. Charges of operation of it represent a significant amount of a budget item. Operator of public lighting tries to rationalize and cost reduction for this reason. Consumption decreased by using more efficient light sources and more efficient optical materials in the past. Currently, the reconstructions are focused on exchange of lamps with more efficient LED.

Another potential for reducing of consumption and increasing of efficiency is adaptive control of public lighting The simplest control system is based on requirement change in late night hour. The control system reduces luminous flux and also reduction of lamp power consumption. This system use the principle of lower requirements in late night, when streets are less used and street can be reclassified to a lower class. Reducing the power consumption of lamp shall be realized individual in the lamp (dimmable ballast) or central in the cabinet (voltage regulator in the control cabinet)

Next step for increasing the efficiency is adaptive control of lighting. In this control is the luminous flux and lamp consumption regulated mainly under street utilization. This system reduce lighting level to minimum (typically 10\%) if no users is using street lighting. Actual consumption of lamps is depending on current lighting profile. Adaptive lighting change luminous flux often and in wide spectrum. This often changing is LED lamp most suitable. Lamps with discharge light sources are not recommended.

Some new adaptive systems of public lighting can shortly increase luminous flux over standard power. It is in case if on road is accident or ambulance, police or firefighters are passing the road. These increases are for safety of drivers and pedestrian users. These systems require communication between the emergency vehicle and the lighting system. Some system can detect color of emergency car flashing without communication. That are very sophisticated solutions and that are at the stage of studies.

\section{Operation profiles for adaptive lighting}

The topic of operation profiles is particularly described in standard prEN 13201-5. Typical lighting control profiles include:

- Full control profile: Characteristic for lighting systems with simple switch features such as timers or photocells.

- Multi-level control profile: made up of two or more times intervals within the day course, during which have lamps different power consumption and provide different light levels in accordance with the classification of roads in lighting classes (according to EN 13201-2) for each of the intervals.

- Night lighting turning off: sometimes used (especially in smaller towns) saving electricity safety reasons, however, this method of investigation cannot be accepted.

- Lighting control using sensors of movement of vehicles and persons (Fig. 1): If the sensors detect movement of vehicles or persons lighting level is adapted. Multilevel regulated control profile is "carve" at times when traffic is not detected. The luminaries are then switches to lower lighting levels. In the night hours for this purpose it defines a new, third light level is a minimum of security (for safe movement in the event of loss detection, looking out of windows to the darkness ...) and which thus also maintains lamps in standby lighting. This mode is particularly suitable for LED lamps that can be easily managed at different levels. Cutouts in Fig. 1 and subject to detection are not periodic. This control profile is especially suitable for residential areas.

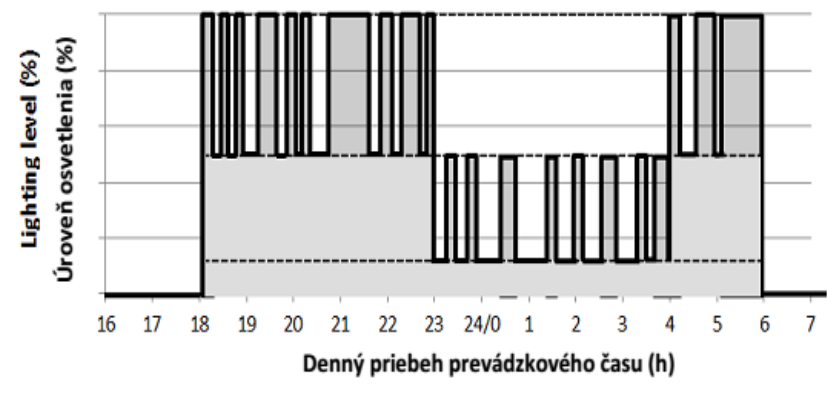

Fig.1. Lighting level profile in public lighting with movement sensors

\section{Efficiency of adaptive lighting}

For full control profile it is usually considered the annual operating time of public lighting 4000 hours. With other operating modes it is usually sufficient to combine an annual operating time of each light level with the appropriate system input and in the case of systems with sensors and the probability of detection. In this way the operation of the lighting ratio calculated $\mathrm{c}_{\mathrm{op}}$. Typical values of the coefficient operation of lighting control profiles for different states are in tab. 1, the values in the table were determined under the following conditions:

- Full profile: 4,000 hours at full power $P$

- Two-level profile: 2,175 hours at full power $\mathrm{P}$ and 1825 hours at reduced power 0,7.P the level of lighting reduced to $50 \%$

- Turn off the light at night: like the two-level profile, but with zero input during 1825 night hours (loss of service) - Three-level profile with sensor: 2175 hours of two-level 
control between $100 \%$ and $60 \%$ of the input of the system with a probability of detection of $80 \%$ and a reduced 1825 hours of two-level control between $20 \%$ and $60 \%$ of the input of the system with probability detecting $20 \%$

Table 1. Typical value of coefficient of operation

\begin{tabular}{|c|c|}
\hline Operation profil & $\mathrm{C}_{\mathrm{op}}(\%)$ \\
\hline Full profile & 100,0 \\
\hline Two-level profile & 86,3 \\
\hline Three-level profile & 62,8 \\
\hline Turn off the light in the night & 54,4 \\
\hline
\end{tabular}

This assessment is used to calculate the AECI (Annual Energy Consumption Indicator). From this it is to see the potential savings from the different levels of management.

\section{Technical solution}

Adaptive public lighting networks describe several studies. The commencement of this technology into practice is slow. Reconstruction with adaptive technologies is a significant investment and technology is not sufficiently adjusted. One of possible solution is described on Fig. 2. On lamppost are placed motion sensors close lamps. These motions detect and signals are process with algorithms. Control unit increase or decrease lighting level in dependence street using. All lighting levels have to satisfy standard requirements for illuminance and luminance. Algorithms for control have to take in to account:

- View a user in the direction of walking or driving

- View a user to the back

- View a user to surroundings, sidewalks and other lanes of street and roads

- View in all directions from junctions

Algorithm and processor have to switch lighting level ahead of using time. Switching to lower level have to have delay for standing people or for leaving people from street.

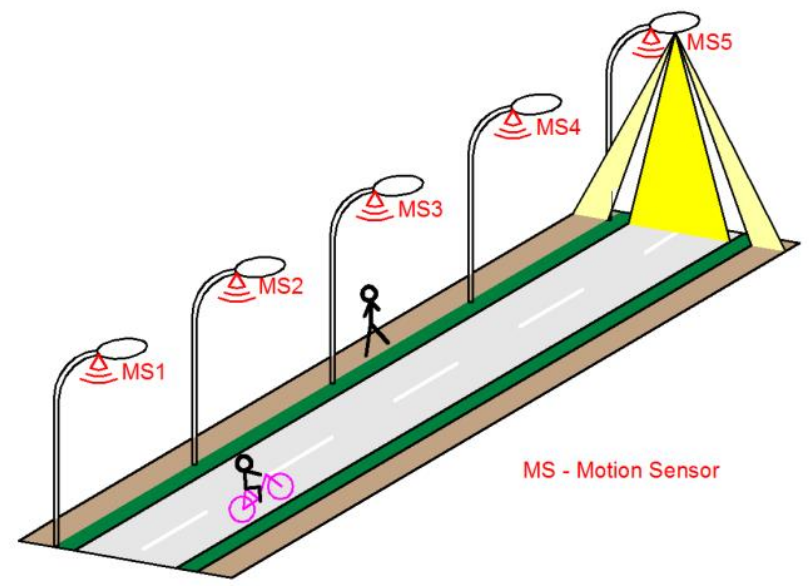

Fig.2. Adaptive street lighting

Advanced technologies can separately manage the lighting in different parts of street. For example, lighting on the road may not be $100 \%$ for the case of a pedestrian on the sidewalk and on the road is not vehicle. These algorithms require control of individual LED chips.

Laser sensors using can evaluate the size of a moving object, its speed, direction and distance from the sensor. Al described technical solution required visibility from sensors to street and surrounding of street. Usually collect data from sensors and control of the luminous flux provided by the control unit located in the supply cabinet. A solution for spacious area is necessary to ensure communication between the controller, lamps and sensors and also harmonize their assistance.

Engineering constraints
At present, the biggest problem is appropriate selection of the motion sensor and the sensitivity settings. Typical motion detectors are:

- Passive infrared detector

- Infrared fence

- Microwave sensors

- Laser Detector

These sensors are nowadays at a high level but usually are developed for the detection of people indoors or in conjunction with other sensors to protect the exterior prior to unauthorized entry. Adapting to detect the movement of people on roads would almost always require some adjustments to eliminate false impulses eg .:

- Weather (rain, snow, fog)

- The effects of movement greenery and trees weather wind - Impact of animal movements

Other complications may represent dirt on the sensor. The using of sensitive detectors requires regular maintenance. For the less sensitive sensor will again be required to use a larger amount. A major problem of adaptive lighting control is shielding the various structures and greenery. Often, that close communication is dense greenery, billboards, etc., which may prevent the motion detector to respond properly to the proximity of people.

\section{Design of adaptive lighting}

At present design of adaptive lighting it is not just a simple engineering works but also are required experiments. It is the result of a small amount of information and experience. Slovakia has implemented two pilot projects. $\mathrm{He}$ is eliminating a lot of trouble choosing communication where there is green and the street is narrow with a single path. PIR sensors are used placed in the lanterns. The second pilot project aims to solve more technical problems and analyzes of the impacts. As part of this project are also involved authors of this paper. Current assessments are carried out technical solutions and measuring the lightproducing and electrical parameters. Light parameters provide information on changes in the management of lighting. Electrical parameters give information on saving energy and impacts on supply.

In Austria is currently operated way with precision adaptive lighting. It is set up for movement an some parts are also setup for adapting of weather condition.

As the proposal adaptive lighting in most cases requires an individual approach, the optimal approach would be to use existing programs when designing the solution.

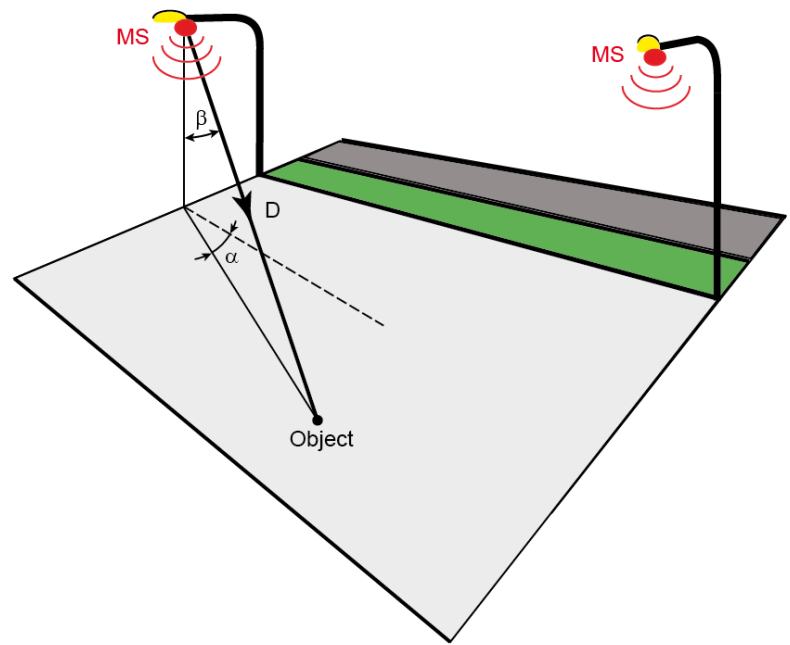

Fig.3. Motion sensor settings

Modeling programs for light calculation encompasses modeling obstacles. When choosing and setting up 
sensors, it is possible to use these programs. In simplified form it can be assumed that if the sensor closer to the lamp and sensor sees the same subjects which lamp illuminates. In Fig. 3 and of formula (1), the selection and adjustment of the sensor so that the distance of a moving object as a or below the resolution of the sensor.

$$
\text { (1) } \bar{D}=(\alpha, \beta, D)
$$

where: $\alpha$-horizontal angle, $\beta$-vertical angle, $D$ - distance from sensor.

\section{Selecting a streets for adaptive lighting}

It is one of the most important steps in design adaptive public lighting. If a rational solution is searching it is appropriate that at all costs seek solutions for complex communication and heavily used communication.

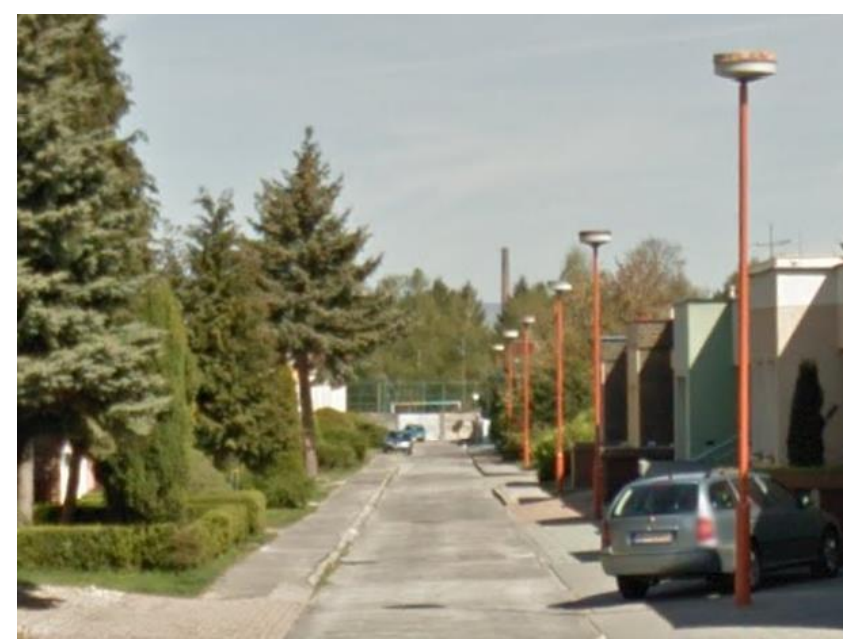

Fig.4. Apposite example of street situation

On Fig. 4 is an example of a suitable communication. Communication is located in a residential area, which represents a significant savings potential. The lighting system is before reconstruction. When placing the sensor near the pole-mounted luminaires problems arise with obstacles. Distance poles and breadth of communication is not great, so just standard sensors.

The communication unsuitable for adaptive lighting features is central parts of towns and routes with frequent movement of people and vehicles because of the long payback. It is also not advisable to install adaptive lighting of the park and winding communications. In these cases, the need to install a more sensors, and a higher probability of false detect or undetected of movement.

\section{Conclusion}

Public lighting is currently designed and operated to meet the standard requirements. But often the case that the communication is illuminated when there are no walkers of drivers. Some communications are illuminated by more than half the time without use, which offers potential savings. Since adaptive lighting is a relatively new technology, it is necessary to responsibly approach to tackling order to avoid rapid and inconsistent solutions. The positive is that penetrate the first pilot projects that enable designers to provide practical information and operator experience to know what to expect from the new technology. Because of these innovative technology municipalities raises concerns about the reliability of the solution.

This paper is supported by the agency VEGA MŠVVaŠ SR under Grant No. VEGA 1/1100/12 „Smart grid as part of power distribution networks - new measurement methods and consumption control methods"

\section{References}

[1] prEN 13201-5 Road Lighting - Performance Requirements

[2] Schréder, Smart Control for Efficient Lighting

[3] CIE 115: Lighting of Roads for motor and Pedestrian Traffic, 2010

[4] Skoda, J, Naxant, P. The reduction in electricity consumption through proper lighting, In proc.> EPE - Electric Power Engineering 2009,. Brno University of Technology: Brno

[5] Sokansky, K., Novak, T.: Energy savings in public lighting, Przeglad Elektrotechniczny, $84(8)$, pp. $72-74,2008$

\section{Authors}

The address for correspondence, e.g. name with title, address of the institution, e-mail address, should be included at the end of the article,

\section{Authors:}

Ing. Peter Janiga, PhD., Slovak University of Technology in Bratislava, Faculty of electrical engineering and information technology, llkovičova 3, Bratislava, Slovak Republic, e-mail: peter.janiga@stuba.sk

Doc. Ing. Dionýz Gašparovský, PhD., Slovak University of Technology in Bratislava, Faculty of electrical engineering and information technology, Ilkovičova 3, Bratislava, Slovak Republic, e-mail:dionyz.gasparovsky@stuba.sk

Ing. Michal Barčik, Slovak University of Technology in Bratislava, Faculty of electrical engineering and information technology, Ilkovičova 3, Bratislava, Slovak Republic, e-mail: michal.barcik@stuba.sk

Ing. Lukas Lipnický, Slovak University of Technology in Bratislava, Faculty of electrical engineering and information technology, Ilkovičova 3, Bratislava, Slovak Republic, e-mail: lukas.lipnicky@stuba.sk 